\title{
Diversidade de Carabidae (Coleoptera) Amostrados em Áreas de Reflorestamento de Mata Ciliar e Fragmento Florestal, no Estado do Paraná
}

\author{
Tamara Quinteiro1 ${ }^{\bowtie}$, José Lopes ${ }^{1}$ \& Ivan Carlos Fernandes Martins²
}

1.Universidade Estadual de Londrina, e-mail: tamaraquinteiro@yahoo.com.br (Autor para correspondência ${ }^{\bowtie}$ ), jea@uel.br. 2. Universidade Estadual Paulista, Faculdade de Ciências Agrárias e Veterinárias, e-mail: carabideos@yahoo.com.br.

\section{EntomoBrasilis 5 (5):217-222 (2012)}

Resumo. Carabidae são Coleoptera com a maioria de suas espécies apresentando hábito alimentar predatório. O objetivo do presente trabalho foi estudar a diversidade e abundância da família Carabidae (Coleoptera) em áreas de fragmento florestal e em áreas de reflorestamento de mata ciliar, evidenciando a importância deste grupo como indicador da biodiversidade em relação ao sucesso do reflorestamento. Os besouros foram amostrados por meio de armadilhas de solo pitfall, em fragmentos florestais e reflorestamentos de mata ciliar em três municípios do estado do Paraná. A abundância de Carabidae foi maior nos reflorestamentos de mata ciliar. A espécie Odontochila nodicornis (Dejean) foi, significativamente, a mais abundante e encontrada em todas as áreas estudadas. Houve similaridade da riqueza de carabídeos encontrada no fragmento florestal remanescente com a riqueza constatadas nos reflorestamentos, mesmo naqueles onde as coletas foram realizadas distante $3 \mathrm{Km}$ do fragmento ou nas áreas de reflorestamento que não apresentavam conexão com o fragmento remanescente. Tetracha brasiliensis (Kirby) foi coletado quase que exclusivamente no reflorestamento sem conexão com o fragmento. Utilizando-se o teste de Kruskal-Wallis, não se constatou atratividade pelas diferentes iscas, no entanto verificou-se diferença significativa entre o número coletado nas armadilhas com iscas, quando comparado com o controle. A maior concentração de carabídeos coletados foi no período de dezembro a fevereiro, estação correspondente ao verão para a região estudada. A similaridade da riqueza de carabídeos encontrada entre os fragmentos de floresta e os reflorestamentos de mata ciliar, pode sugerir sucesso do método de reflorestamento, estando avançando para condições de característica primária.

Palavras-chaves: Abundância; Biodiversidade; Bioindicadores; Protocolo de avaliação.

\section{Diversity of Carabidae (Coleoptera) Samples in Areas of Riparian Reforestation and Forest Fragment, in the State of Paraná}

Abstract. Carabidae are Coleoptera whose most species have a predatory eating habit. The purpose of this paper was to study the diversity and abundance of Carabidae (Coleoptera) family in forest fragment areas and in reforestation areas of riparian vegetation, evidencing the importance of this group as a biodiversity indicator regarding the reforestation success. Beetles were sampled using soil pitfall traps in forest fragments and reforestation of riparian vegetation in three municipalities the state of Parana. The abundance of Carabidae was higher in riparian reforestation. The species Odontochila nodicornis (Dejean) was the most significantly abundant and found in all studied areas. There was a similarity in richness of Carabidae found in the remaining forest fragment, being the wealth found in reforestation, even where samples were collected $3 \mathrm{~km}$ away from the fragment or in reforestation areas that did not have any connection with the remaining fragment. Tetracha brasiliensis (Kirby) was almost exclusively collected in reforestation unrelated to the fragment. Using the Kruskal-Wallis test, it was not noted any attraction of different baits, but there was a significant difference between the collection number in baited traps compared with the control. The highest concentration of Carabidae was collected from December to February, period corresponding to the summer season for the studied region. The similarity on the richness of Carabidae found between forest fragments and reforestation of riparian vegetation may suggest the reforestation method success, being able to advance to the primary characteristic.

Keywords: Abundance; Assessment Protocol; Biodiversity; Bioindicators.

$\mathbf{O}$ riginalmente, o estado do Paraná possuía $85 \%$ de sua área coberta por formações florestais classificada como Floresta Estacional Semidecídua (MAAcK 2002). Esta vegetação original dominante sofreu um processo intenso de fragmentação e perda de habitat, resultando numa paisagem composta de pequenos fragmentos, que hoje representam apenas $7,5 \%$ da cobertura florestal nativa (PRIMACK \& RodrigUes 2001).

$\mathrm{Na}$ avaliação ambiental depara-se com a necessidade de ações de recuperação ambiental, principalmente nas encostas de morros, nascentes, margens de rios e lagos. Ação comum tem sido o reflorestamento, que consiste na modificação de um ambiente qualquer, seja ele estéril ou perturbado, através da introdução de populações de organismos. As populações tendem a modificar o ambiente físico construindo condições favoráveis para outras populações, atingindo um equilíbrio entre as partes bióticas e abióticas (Odum 2004).
As transformações no ambiente e consequente fragmentação florestal que ocorreram na região norte do Paraná, resultaram na formação de fragmentos de habitats circundados por matriz urbana ou agropecuária, causando mudanças físicas e biológicas na estrutura destes fragmentos. Alguns insetos, como os coleópteros, podem ter suas atividades biológicas (polinização, decomposição, predação, dispersão de sementes e reciclagem de nutrientes) afetadas com a fragmentação florestal, acarretando ainda, desequilíbrios como a invasão de pragas (PETRONI 2008).

Dentre os besouros, os da família Carabidae são, em sua grande parte, importantes predadores de outros insetos e a dinâmica de suas populações podem ser indicativos de outras variáveis ambientais, como a população de presa e consequentemente a condição do habitat exigido por esta última (Costa Lima 1952). Esta família é uma das mais numerosas de besouros, representada por aproximadamente 40.000 espécies conhecidas em todo o 
mundo (LÖVEI \& SUdERLAND 1996).

Carabídeos têm sido utilizados como organismos indicadores em avaliações de poluição ambiental, classificação de habitat para a conservação ambiental, caracterização de solo com relação aos nutrientes, ou como indicadores de biodiversidade (LöveI \& Suderland 1996). Segundo Brown JR (1991), Carabidae é um grupo bioindicador, pois possui boa parte das espécies com alta fidelidade ecológica, são bastante diversificados taxonômica e ecologicamente, fáceis de serem coletados em grandes amostras e funcionalmente importantes nos ecossistemas. Formam, ainda, grupos relativamente bem conhecidos taxonomicamente e identificáveis, além de se associarem intimamente com outras espécies e recursos. Os carabídeos têm sido ainda sugeridos para uso como indicadores em programas para levantamento da biodiversidade por apresentarem grande variabilidade morfológica, comportamental e por serem sensíveis a mudanças ambientais (Niemelä \& KotZe 2000).

Trabalhos enfatizando comunidades de coleópteros predadores em áreas de fragmento e reflorestamento são escassos. Este levantamento visou à identificação de espécies que possam ser utilizadas como bioindicadores e obter dados de sua dinâmica populacional que possam ser correlacionados com o processo de avaliação de sucesso nos programas de reflorestamento

Estabeleceu-se a hipótese de que nos fragmentos florestais seria encontrada uma maior diversidade de espécies da família Carabidae e menor abundância de indivíduos quando comparados aos ambientes de reflorestamento.

O objetivo do presente trabalho foi estudar a diversidade e abundância da família Carabidae (Coleoptera) em áreas de fragmento florestal e em áreas de reflorestamento de mata ciliar, evidenciando a importância deste grupo como indicador da biodiversidade em relação ao sucesso do reflorestamento.

\section{MATERIAL E MÉTODOS}

Foi realizado um amplo estudo da entomofauna de solo objetivando possível aproveitamento destes dados no protocolo de avaliação do sucesso de recuperação de áreas degradadas. Os dados sobre Carabidae estão envolvidos neste contexto.

As coletas foram realizadas no estado do Paraná, Brasil, nos municípios de Alvorada do Sul, Primeiro de Maio e Rancho Alegre, em reflorestamentos de mata ciliar nas margens do Reservatório de Capivara (Rio Paranapanema, $22^{\circ} 47$ ' $45^{\prime}$ S e $51^{\circ}$ Oo' 12 ” W) e em fragmentos florestais adjacentes (Figura 1).

Em Rancho Alegre foram amostradas três áreas, sendo uma de fragmento florestal e duas áreas de reflorestamento, uma conectada ao fragmento, onde as armadilhas foram instaladas na borda do reflorestamento imediatamente após o término do fragmento, e outra localizada próximo à rodovia PR 323, a qual não apresenta conexão com o fragmento florestal.

Em Alvorada do Sul as coletas ocorreram em duas áreas, sendo uma em fragmento florestal e outra em seu reflorestamento adjacente. As armadilhas instaladas no reflorestamento estavam a $500 \mathrm{~m}$ do fragmento.

Em Primeiro de Maio o estudo foi desenvolvido apenas em uma área de reflorestamento de mata ciliar e as armadilhas foram instaladas a aproximadamente $3 \mathrm{~km}$ de seu fragmento. Os reflorestamentos apresentavam, no início do período das coletas, respectivamente, cinco anos, quatro anos e meio, sete anos e seis anos.

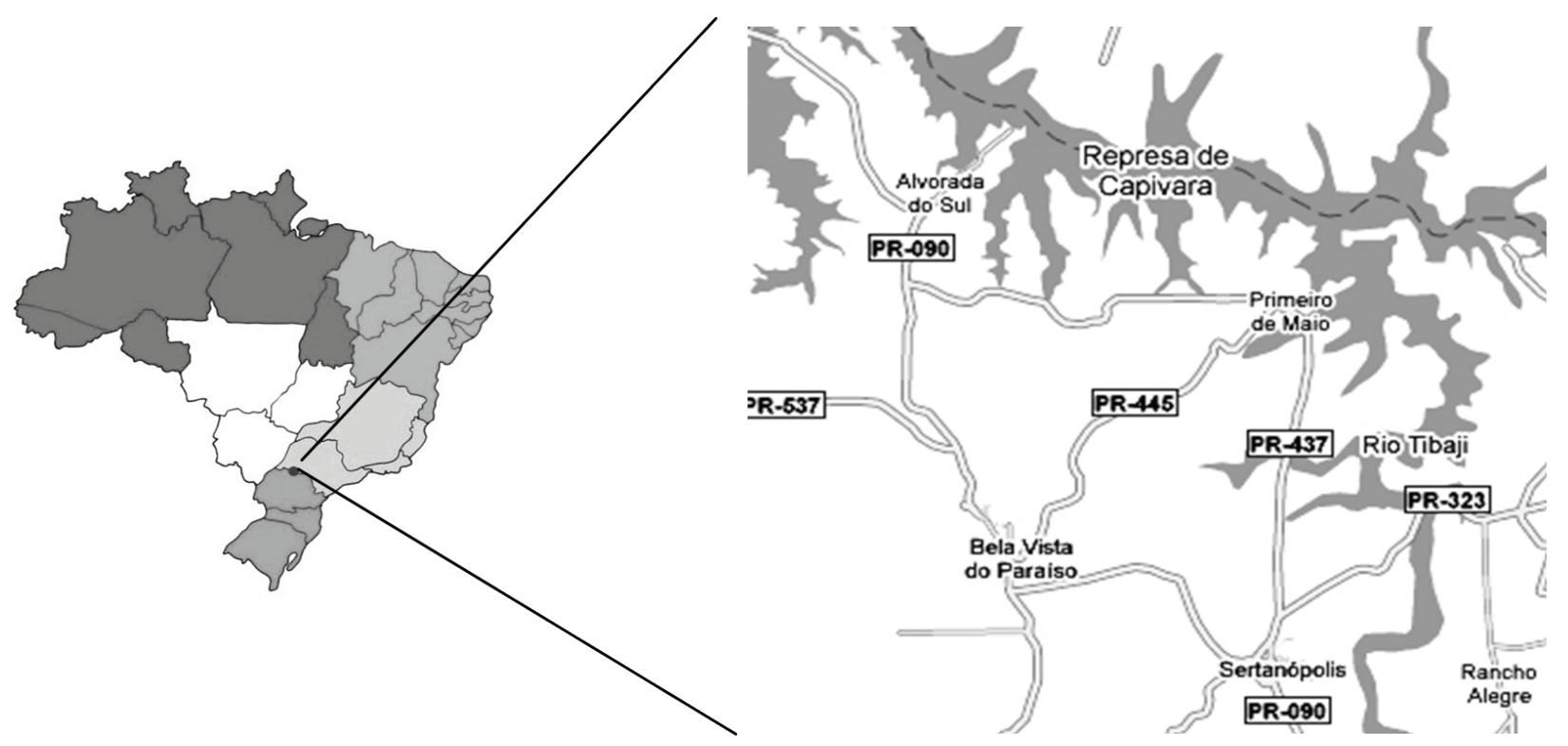

Figura 1. Localização das áreas de estudo da família Carabidae, nos municípios de Alvorada do sul, Primeiro de Maio e Rancho Alegre, PR.

Os reflorestamentos foram realizados por meio de plantios mecanizados, em espaçamento 2x3 m, sem adubação, utilizando cerca de 40 espécies nativas, sendo as mais representativas as espécies pioneiras e secundárias iniciais como a Guazuma ulmifolia Lam. (mutambo), Heliocarpus americanus L. (jangada branca), Trema micrantha (L.) Blume (crindiúva) e Croton urucurana Baillon.

As coletas foram realizadas no período de maio de 2007 a abril de 2008, em intervalos de 15 dias. Foram instaladas sete armadilhas do tipo pitfall modificadas de MEDRI \& LOPEs (2001) em cada área de estudo. A armadilha consiste em um recipiente plástico de 23 $\mathrm{cm}$ de comprimento por $9,5 \mathrm{~cm}$ de diâmetro. Na borda superior de cada recipiente foi acoplado um frasco (do tipo porta filme fotográfico) através de um fio de arame, contendo a isca. No recipiente plástico foi inserido $150 \mathrm{~mL}$ de solução de formol $4 \%$ como líquido mortífero e fixador, com adição de algumas gotas de detergente líquido para quebrar a tensão superficial (Figura 2).

Para proteger as armadilhas contra possíveis ataques de mamíferos e outros vertebrados, foi colocada uma armação de ferro em forma de mesa de $60 x 60 \mathrm{~cm}$ e pés $\mathrm{com} 25 \mathrm{~cm}$ de altura. Na parte superior da estrutura foi fixada uma tela com linha de nylon. A proteção foi fixada ao solo acima da armadilha, enterrando os pés de tal forma a permanecer um espaço de $5 \mathrm{~cm}$ entre o solo e a armação, o que permite a passagem dos insetos. 
As iscas atrativas utilizadas foram fezes de porco, carne bovina moída e banana madura, já que o experimento global destinavase ao levantamento geral da entomofauna de solo. Em cada local foram instaladas duas armadilhas para cada tipo de isca e uma armadilha sem atrativo, usada como controle, totalizando sete armadilhas por local. Estas foram dispostas em linha reta no sentido borda-interior da área, com distanciamento de $10 \mathrm{~m}$ entre elas.

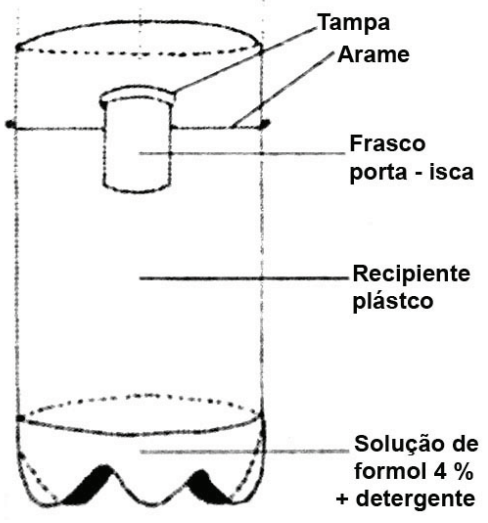

Figura 2. Esquema da armadilha de solo utilizada para a captura dos exemplares da família Carabidae nos municípios de Alvorada do Sul, Primeiro de Maio e Rancho Alegre, PR.

Para se evitar o efeito de borda na área de fragmento, adentrouse aproximadamente $100 \mathrm{~m}$ para a instalação da primeira armadilha. Isso não foi possível nos reflorestamentos, pois esses se apresentam em faixa estreita. Quinzenalmente as iscas eram trocadas, o conteúdo das armadilhas era coado em peneira de coar óleo com malha de $200 \mu \mathrm{m}$ e transferido para frascos de transporte com álcool 70\%.

Para análises dos dados calculou-se: a frequência absoluta de captura de cada espécie para a comparação quanto a sua ocorrência na área; o índice de diversidade de Shannon - Wiener $\left(H^{\prime}\right)$, considerando tanto a abundância quanto a diversidade de espécies de um determinado local; o índice de similaridade de Sorenson que compara a composição de espécies de cada ambiente estudado, em uma esfera local (diversidade $\alpha$ ). Também foi realizado a Correlação Linear de Pearson, que examina cada par de variáveis de medida e determina se as duas variáveis tendem a se moverem juntas, e Anova (fator único), que consiste em uma simples análise da variância dos dados em duas ou mais amostras. As análises estatísticas foram realizadas nos programas DivEs v2.o (RodRIGUES 2005), PAST e EXCEL.

\section{RESULTADOS E DISCUSSÃO}

Foram coletados 734 exemplares de coleópteros da família Carabidae, identificados em 20 espécies (Tabela 1).

A abundância, fazendo-se a média do total obtido para os dois fragmentos e do total obtido para os quatro reflorestamentos, foi maior nos reflorestamentos de mata ciliar $(67,27 \%)$ quando comparado com a abundância obtida nas áreas de fragmento florestal (32,72\%) (Tabela 1).

As espécies encontradas exclusivamente em fragmentos foram Abaris basistriata Chaudoir, Lebiini sp.2, Lebiini sp.4, Tichonilla festiva (Tschitscherine), Sphalera plaumanni Liebke, todavia, apresentaram-se como espécies singleton (Tabela 1). Em Jaboticabal, SP, CividAnEs et al. (2003) encontraram 37 indivíduos ( $0,07 \%$ do total) de $A$. basistriata em áreas de hortaliças e não a registraram em fragmento florestal. Entretanto MARTINs et al. (2009) verificaram que $A$. basistriata é uma espécie abundante tanto em área agrícola quanto em fragmento florestal.

As espécies Athrostictus sp.1, Cymindis sp.1, Galerita sp.1, Lebiini sp.3, Pterostichini sp.1, Pterostichini sp.2, Scaritini sp.1, Pseudaptirus albicornis Castlenau, 1834, Selenophorus alternans Dejean e Pentacomia cupricollis Kollar, foram registradas com exclusividade para os reflorestamentos de mata ciliar, também com baixa frequência e abundância (Tabela 1).

Tabela 1. Frequência Absoluta de Carabidae coletados com armadilhas pitfall, em áreas de fragmento florestal e reflorestamento de mata ciliar nos municípios de Alvorada do Sul, Primeiro de Maio e Rancho Alegre, PR, no período de maio de 2007 a abril de 2008.

\begin{tabular}{|c|c|c|c|c|c|c|c|}
\hline \multirow[t]{2}{*}{ Espécie } & \multicolumn{3}{|c|}{ Rancho Alegre } & \multicolumn{2}{|c|}{ Alvorada do Sul } & \multirow{2}{*}{$\begin{array}{c}\begin{array}{c}\text { Primeiro de } \\
\text { Maio }\end{array} \\
\mathbf{R}\end{array}$} & \multirow[t]{2}{*}{ Total (\%) } \\
\hline & $\mathbf{F}$ & $\mathbf{R}$ & R- 2 & $\mathbf{F}$ & $\mathbf{R}$ & & \\
\hline Abaris basistriata & 1 & & & & & & $1(0,13)$ \\
\hline Athrostictus sp.1 & & 4 & & & & & $4(0,54)$ \\
\hline Calosoma granulatum & & 1 & & 1 & & & $2(0,27)$ \\
\hline Cymindis sp.1 & & & 1 & & & & $1(0,13)$ \\
\hline Galerita sp.1 & & & 1 & & & 1 & $2(0,27)$ \\
\hline Lebiini sp.1 & 1 & 1 & & & & & $2(0,27)$ \\
\hline Lebiini sp.2 & 1 & & & & & & $1(0,13)$ \\
\hline Lebiini sp.3 & & & & & & 1 & $1(0,13)$ \\
\hline Lebiini sp.4 & & & & 1 & & & $1(0,13)$ \\
\hline Loxandrus subvittatus & & 1 & & 1 & & & $2(0,27)$ \\
\hline Pterostichini sp.1 & & & & & & 1 & $1(0,13)$ \\
\hline Pterostichini sp.2 & & & & & 1 & & $1(0,13)$ \\
\hline Tichonilla festiva & 1 & & & 1 & & & $2(0,27)$ \\
\hline Scaritini sp.1 & & & 2 & & & & $2(0,27)$ \\
\hline Sphalera plaumanni & 1 & & & & & & $1(0,13)$ \\
\hline Pseudaptirus albicornis & & & & & & 1 & $1(0,13)$ \\
\hline Selenophorus alternans & & 1 & & & & & $1(0,13)$ \\
\hline Tetracha brasiliensis & 1 & 1 & 58 & 1 & & 1 & $62(8,44)$ \\
\hline Pentacomia cupricollis & & 1 & & & & & $1(0,13)$ \\
\hline Odontocheila nodicornis & 131 & 93 & 140 & 1 & 130 & 150 & $645(87,87)$ \\
\hline Total de espécimes & 137 & 103 & 202 & 6 & 131 & 155 & $734(100 \%)$ \\
\hline Total de espécies & 7 & 8 & 5 & 6 & 2 & 6 & \\
\hline Equitabilidade & 0,132 & 0,234 & 0,441 & 1 & 0,064 & 0,108 & \\
\hline $\mathbf{H}^{\prime}$ & 0,112 & 0,212 & 0,308 & 0,778 & 0,019 & 0,084 & \\
\hline
\end{tabular}

Fragmento (F), reflorestamento (R), segundo reflorestamento em Rancho Alegre (R-2) 
As espécies encontradas nos dois ecótopos estudados foram Calosoma granulatum Perty, Lebiini sp.1, Loxandrus subvittatus Straneo, Tetracha brasiliensis Kirby e Odontochila nodicornis (Dejean) (Tabela 1). Dentre estas, T. brasiliensis predominou no reflorestamento. Cividanes \& Santos-Cividanes (2008) e Martins et al. (2009) relataram esta espécie com maior ocorrências em áreas agrícolas quando comparado a áreas naturais e seminaturais. Os carabídeos são específicos na preferência do habitat, que frequentemente são utilizados para caracterizar tais locais, existindo espécies que predominam em florestas, outras em culturas agrícolas ou outros hábitats (LövEI \& SUNDERLAND 1996). No entanto, o baixo número de exemplares de cada espécie capturada nesta pesquisa impossibilita afirmar a predominância de hábitats.

O. nodicornis foi a espécie mais abundante (87\%), encontrada em todas as áreas estudadas (Tabela 1), destacando-se das demais de forma significativa, comprovado pelo teste de Análise de Variância $\left(p=8,29^{-0,6}\right)$. Estes resultados estão de acordo com o observado por MARTins et al. (2009), que em estudo realizado em áreas de plantio direto, convencional (soja/milho) e fragmento florestal, constatou alta abundância da espécie distribuída em todas as áreas estudadas. Esta ampla distribuição e alta abundância podem indicar tratar-se de espécie com valência ecológica que a capacita explorar tanto ambientes com características primitivas, quanto os antrópicos.

ODum (1986), afirma que no número total de espécies pertencentes a uma comunidade, uma percentagem relativamente pequena é abundante ou dominante, representada por grandes números de indivíduos, e uma grande porcentagem é rara. LöveI \& SUNDERLAND (1996), ao fazerem um levantamento bibliográfico sobre a densidade de Carabidae em 14 países da Europa e América do Norte, relataram que a densidade de adultos em culturas anuais foi de 32 indivíduos por metro quadrado, enquanto em florestas ocorreram em número extremamente baixo $\left(2 / \mathrm{m}^{2}\right)$. CLARK et al. (1997), estudando a ocorrência de carabídeos em culturas anuais, perenes e em habitat natural constituído de árvores, arbustos e gramíneas, obtiveram abundância reduzida no hábitat florestal, atribuindo o fato, ao baixo número de presas. No presente estudo, ao redor das áreas de fragmento florestal e reflorestamento existiam plantios de milho e, ou, trigo, o que pode também ter contribuído para o baixo índice de espécimes coletados.
O índice de Shannon - Wiener (H') (RoDRIGUEs 2005) indica uma maior diversidade para o fragmento em Alvorada do Sul ( $\mathrm{H}^{\prime}=$ 0,778), significativamente diferente das outras áreas, constatada pelo Teste de t de Student $(\mathrm{p}<0,05)$. Este resultado pode estar influenciado pela baixa abundância registrada, já que o teste leva em consideração este fator. Também foi constatada diferença significativa na diversidade entre o reflorestamento onde as armadilhas estavam instaladas em continuidade ao fragmento, o reflorestamento em que as armadilhas estavam a $500 \mathrm{~m}$ do fragmento e o reflorestamento com armadilhas instaladas a $3 \mathrm{Km}$ do fragmento. O reflorestamento contínuo ao fragmento foi o que demonstrou maior diversidade específica em relação aos outros reflorestamentos, todavia com menor abundância (Tabela 1).

Thomazini \& Thomazini (2000), afirmam que florestas secundárias também podem abrigar grande diversidade de insetos, sendo que a variação na idade e tamanho das mesmas pode influenciar essa diversidade. No caso da utilização de florestas secundárias, o reflorestamento localizado em Alvorada do Sul, com armadilhas instaladas a $500 \mathrm{~m}$ do fragmento, foi o local que se coletou o menor número de espécies. Este reflorestamento é o que possui menor idade e possui a vegetação pouco densa e muito espaçada. A discrepância no total de espécies coletadas foi maior entre o reflorestamento e seu fragmento em Alvorada do Sul, quando comparado com o total de espécies que foi similar entre o reflorestamento em Rancho Alegre com o seu fragmento (Tabela 1). Este resultado pode indicar um estágio primário de colonização no reflorestamento em Alvorada do Sul, onde poucas espécies, mas com alta abundância, tendem a colonizar o novo hábitat.

Aplicando-se o índice de Equitabilidade (Rodrigues 2005) constatou-se que as espécies estão regularmente distribuídas apenas no fragmento em Alvorada do Sul. Este resultado se deve ao fato de se ter coletado seis espécies singleton.

O índice de Shannon e Equitabilidade foi aplicado de forma especial sem a espécie $O$. nodicornis, já que essa espécie foi a dominante nas coletas e, portanto, pode estar mascarando os dados. Os resultados dos testes mostraram que as espécies não estão regularmente distribuídas na área de reflorestamento sem conexão com o fragmento em Rancho Alegre e no reflorestamento a $500 \mathrm{~m}$ do fragmento. Quando aplicado o Teste t de Student,

Tabela 2. Frequência de Carabidae coletados com armadilhas pitfall, em diferentes iscas em áreas de reflorestamento de mata ciliar e fragmento florestal nos municípios de Alvorada do Sul, Primeiro de Maio e Rancho Alegre, PR.

\begin{tabular}{|c|c|c|c|c|}
\hline \multirow{2}{*}{ Espécie } & \multicolumn{4}{|c|}{ Iscas } \\
\hline & Controle & Carne & Banana & Fezes \\
\hline Abaris basistriata & & 1 & & \\
\hline Athrostictus sp.1 & & 1 & 3 & \\
\hline Calosoma granulatum & & & & 2 \\
\hline Cymindis sp.1 & 1 & & & \\
\hline Galerita sp.1 & & 1 & & \\
\hline Lebiini sp.1 & & & 2 & \\
\hline Lebiini sp.2 & & 1 & & \\
\hline Lebiini sp.3 & & 1 & & \\
\hline Lebiini sp.4 & & 1 & & \\
\hline Loxandrus subvittatus & & 2 & & \\
\hline Pterostichini sp.1 & & & & 1 \\
\hline Pterostichini sp.2 & & 2 & & \\
\hline Tichonilla festiva & & & & 2 \\
\hline Scaritini sp.1 & 1 & & 1 & \\
\hline Sphalera plaumanni & & 1 & & \\
\hline Pseudaptinus albicornis & 1 & & & \\
\hline Selenophorus alternans & & 1 & & \\
\hline Tetracha brasiliensis & 1 & 31 & 17 & 13 \\
\hline Pentacomia cupricollis & & & 1 & \\
\hline Odontocheila nodicornis & 31 & 294 & 165 & 155 \\
\hline Total de espécimes & $35(4,76 \%)$ & $337(45,91 \%)$ & $189(25,74 \%)$ & $173(23,56 \%)$ \\
\hline Total de espécies & 5 & 12 & 6 & 5 \\
\hline
\end{tabular}


existe diferença significativa de diversidade no reflorestamento em Rancho Alegre sem conexão com o fragmento e no fragmento em Alvorada do Sul em relação a todas as outras áreas. Essa diferença na diversidade do reflorestamento sem conexão com o fragmento com as demais áreas provavelmente foi provocada pela presença de T. brasiliensis que foi abundante apenas nessa área, agindo agora como dominante em relação às outras espécies.

A espécie $O$. nodicornis apresentou abundância praticamente homogênea em todos os ambientes estudados, com exceção no fragmento de Alvorada do Sul, onde apenas um exemplar foi coletado. Todavia, no reflorestamento, onde as armadilhas foram instaladas a $500 \mathrm{~m}$ desse fragmento, dos 137 carabídeos coletados, 130 pertenciam à espécie O. nodicornis (Tabela 1).

Pelaanálisedesimilaridadeentreos habitats a maioria demonstrou similaridade moderada $(30 \%<\mathrm{Cs}<80 \%)$. O reflorestamento, com as armadilhas instaladas a $500 \mathrm{~m}$ do fragmento, apresentou similaridade moderada apenas em relação ao reflorestamento sem conexão com fragmento, essas duas áreas foram a que menos apresentaram diversidade de espécies. O reflorestamento contínuo ao fragmento também não foi similar ao reflorestamento com armadilhas a $3 \mathrm{Km}$ do fragmento. De oito espécies coletadas no reflorestamento contínuo, apenas duas foram encontradas no reflorestamento a $3 \mathrm{~km}$ do fragmento.

A espécie $T$. brasiliensis foi coletada quase que exclusivamente no reflorestamento sem conexão com o fragmento. Como já referido, Cividanes et al. (2003), só capturaram esta espécie em área de cultivo de hortaliças. Mesmo resultado constatado por MARTins et al. (2009), onde esta espécie apresentou preferência por área agrícola quando comparado com área de fragmento florestal adjacente.

Utilizando o teste de Kruskal Wallis com 95\% de significância para o númerototal de carabídeos coletados foiverificado que não houve atratividade pelas iscas $(\mathrm{P}=0,3514)$, apesar de a porcentagem ser maior nas iscas com carne (Tabela 2). Aplicando-se o teste apenas para $O$. nodicornis que foi a mais abundante, também não demonstrou atratividade. Devido ao comportamento predatório desses insetos, iscas não são bons atrativos. Segundo Lovari et al. (1992), presas móveis são detectadas visualmente a uma distância de cerca de $20 \mathrm{~cm}$. Embora não se constate atratividade pelas diferentes iscas, verifica-se diferença significativa entre o número coletado nas armadilhas com iscas, quando comparado com o controle. As iscas exerceram atratividade para insetos coprófagos, necrófagos e frugívoros e estes, por sua vez, como presas, podem ter atraído os Carabidae.

O número de carabídeos coletados foi baixo no período de maio até novembro de 2007 ( 25 espécimes) demonstrando um pico nos meses de dezembro (87), janeiro (306) e fevereiro (211), estação correspondente ao verão. Esses dados estão de acordo com os obtidos por Freitas et al. (2002), no qual o pico populacional de carabídeos foi em dezembro. Para $O$. nodicornis, que foi a espécie mais abundante, houve flutuação populacional comprovada pelo teste de Análise de Variância, obtendo-se uma média de abundância significativa no mês de fevereiro $\left(p=3,6^{-0,8}\right)$. Não houve correlação significativa entre abundância e a temperatura média mensal e com o total da precipitação mensal (Figuras 3 e 4). Dreisig (1981) afirma que a temperatura ambiente pode servir como um regulador na taxa de forrageamento de $C$. hybrida que são induzidas a sair de suas tocas em temperatura média de $28^{\circ}$ C.. Durante a baixa temperatura a subfamília Cicindelinae não é ativa, ficam ao sol para elevar a sua temperatura corporal.

A similaridade da riqueza de carabídeos encontrada nos reflorestamentos contínuo com o fragmento, no reflorestamento sem conexão com o fragmento e no reflorestamento onde as capturas foram realizadas a $3 \mathrm{Km}$ do fragmento, em relação aos fragmentos florestais, pode sugerir sucesso do método de reflorestamento, estando avançando para condições de característica primária. Desta forma, os reflorestamentos apresentam uma estrutura ambiental exigida pelo grupo estudado.

O. nodicornis mostrou-se bem adaptada tanto nas condições ambientais mais preservadas, quanto para áreas antrópicas, indicando tratar-se de uma espécie oportunista com adaptabilidade para áreas antropofisadas.

$T$. brasiliensis se fez presente quase que exclusivamente na área antropofisada, caracterizando-se como espécie oportunista e podendo ser selecionada como indicadora de ambientes alterados.

Não se pode afirmar a preferência de habitat entre as espécies encontradas apenas nos fragmentos e nos reflorestamentos, pois em grande parte só foi encontrado um exemplar de cada espécie. A maior concentração de carabídeos de dezembro de 2007 a fevereiro de 2008 está relacionada com as condições favoráveis da estação do verão.

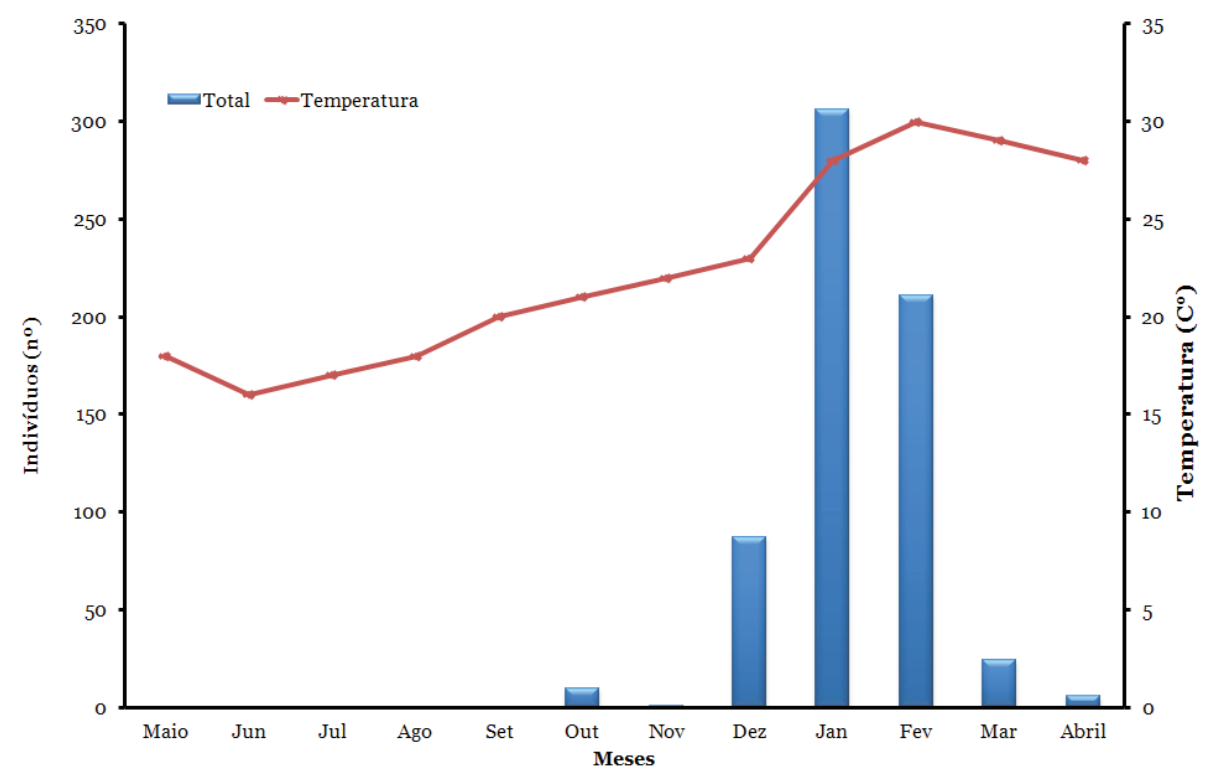

Figura 3. Abundância de $O$. nodicornis coletada em armadilhas de solo em fragmento florestal e reflorestamento de mata ciliar nos municípios de Alvorada do Sul, Primeiro de Maio e Rancho Alegre, Estado do Paraná, correlacionada com a temperatura média mensal, de maio de 2007 a abril de 2008. 


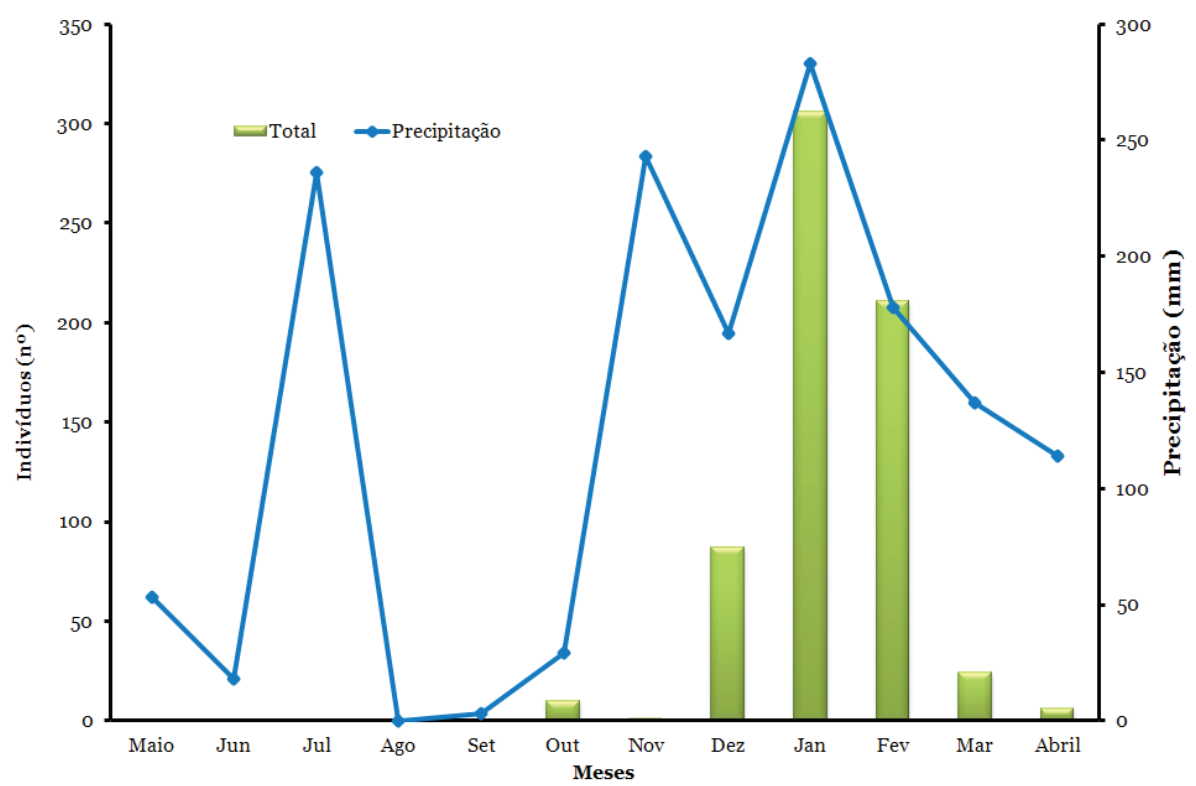

Figura 4. Abundância de O. nodicornis coletada em armadilhas de solo em fragmento florestal e reflorestamento de mata ciliar, nos municípios de Alvorada do Sul, Primeiro de Maio e Rancho Alegre, Estado do Paraná, correlacionada com a precipitação média mensal, de maio de 2007 a abril de 2008.

\section{REFERÊNCIAS}

Brown Jr. K.S., 1991. Conservation of neotropical environments: Insects as indicators. p. 349-404. In: Collins, N.M. \& J.A. Thomas, The Conservation of Insects and Their Habitats. Academic Press: London, 43op.

Cividanes, F.J. \& T.M. Santos-Cividanes, 2008. Distribuição de Carabidae e Staphylinidae em agroecossistemas. Pesquisa Agropecuária Brasileira, 43: 157-162.

Cividanes, F.J., V.P. Souza \& L.K. Sakemi, 2003. Composição faunística de insetos predadores em fragmento florestal e em área de hortaliças na região de Jaboticabal, Estado de São Paulo. Acta Scientiarum. Biological Sciences, 25 : 315-321.

Clark, M.S., S.H. Gage \& J.R. Spence, 1997. Habitats and management associated with common ground beetles (Coleoptera: Carabidae) in a Michigan agricultural landscape. Environmental Entomology, 26: 519-527.

Costa Lima, A.M., 1952. Tomo 7, Coleópteros. In: Insetos do Brasil. Rio de Janeiro: Escola Nacional de Agronomia, 257278.

Dreisig, H., 1981. The rate of predation and its temperature dependence in a tiger beetle Cicindela hybrida. Oikos. 36: 196-202.

Freitas, F.A., M.C. Lacerda, J.C. Zanuncio \& T.V. Zanuncio, 2002. Fauna de coleoptera coletada com armadilhas luminosas em plantio de Eucalyptus grandis em Santa Bárbara, Minas Gerais. Revista Árvore, 26: 5-8.

Lovari, S., L. Favilli, M.P. Eusebi \& F. Cassola, 1992. The effects of prey movement, size and colour in the attack/avoidance behaviour of the tiger beetle Cephalota circumdata leonschaeferi (Cassola) (Coleoptera: Cicindelidae). Ethology Ecology and Evolution, 4: 321-331.

Lövei, G.L. \& K.D. Sunderland, 1996. Ecology and behavior of ground beetles (Coleoptera: Carabidae). Annual Review of Entomology, 41: 231-256.
Maack, R., 2002. Geografia física do Estado do Paraná. Imprensa Oficial, 440p.

Martins, I.C.F., F.J. Cividanes, J.C. Barbosa, E.S. Araújo \& G.Q. Haddad, 2009. Análise de fauna e flutuação populacional de Carabidae e Staphylinidae (Coleoptera) em sistemas de plantio direto e convencional. Revista Brasileira de Entomologia, 53: $432-443$.

Medri, I.M. \& J. Lopes, 2001. Coleopterofauna em floresta e pastagem no norte do Paraná, Brasil, coletada com armadilha de solo. Revista Brasileira de Zoologia, 18: 125 - 133.

Niemelä, J. \& J. Kotze, 2000. Assessing anthropogenic impacts on biodiversity using carabids: a global network. In: International Congress of Entomology, 21. Foz do Iguaçu, Embrapa Soja, 106 p.

Odum, E.P., 1986. Ecologia. Rio de Janeiro, Guanabara, 434p.

Odum, E.P., 2004. Fundamentos de Ecologia. 7. ed. Lisboa: Fundação Calouste Gulbenkian, 927 p.

Petroni, M.D., 2008. Diversidade de Famílias de Coleópteras em Diferentes Fragmentos Florestais no Município de Londrina, PR, Brasil. Dissertação (mestrado em Ciências Biológicas). Universidade Estadual de Londrina - Londrina. 62 p.

Primack, R. \& E. Rodrigues, 2001. Biologia da Conservação. Londrina, Midiograf, 328p.

Rodrigues, W.C., 2005. DivEs - Diversidade de espécies. Versão 2.o. Software e Guia do Usuário. Disponível em: <http://www.ebras.bio.br/dives/> [10 set. 2010].

Thomazini, M.J. \& A.P.B.W. Thomazini, 2000. A fragmentação florestal e a diversidade de insetos nas florestas tropicais úmidas. Rio Branco: Embrapa Acre. 21p. Disponível em <http://www.cpafac.embrapa.br/> [22 mar. 2009].

\section{Recebido em: 03/07/2012}

Aceito em: 07/o8/2012 $* * * * * * * * *$

Como citar este artigo:

Quinteiro, T., J. Lopes, I. C. F. Martins, 2012. Diversidade de Carabidae (Coleoptera) Amostrados em Áreas de Reflorestamento de Mata Ciliar e Fragmento Florestal, no Estado do Paraná. EntomoBrasilis, 5(3): 217-222. Acessível em: http://www.periodico.ebras.bio.br/ojs/index.php/ebras/article/view/255
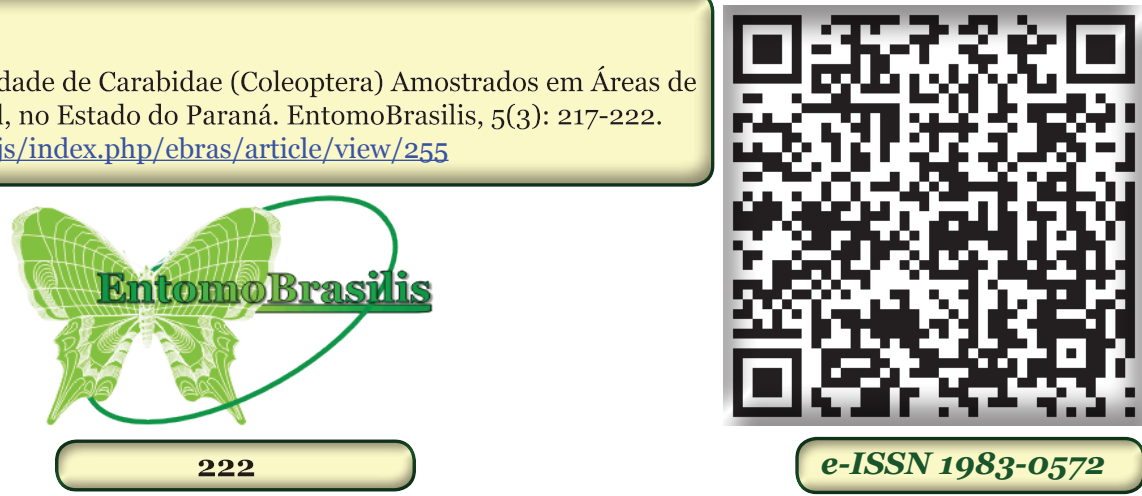